\title{
A new approach to understand liquid injection into atmospheric plasma jets
}

\author{
Dennis Soysal *, Asif Ansar \\ German Aerospace Center (DLR), Institute of Technical Thermodynamics
}

\section{A R T I C L E I N F O}

Available online 20 December 2012

\section{Keywords:}

Diagnostics

Liquid injection

Thermal spraying

High speed imaging

Infrared imaging

\begin{abstract}
A B S T R A C T
Infrared images are used to characterize the atmospheric plasma and the influence of liquid injection into it. In the infrared spectral range low energies of rotational vibrational transitions can be captured which are emitted by hot liquid vapors. These vapor streams enable the qualification of the injection depth. High speed shadowgraphy is used to prove the correlations between vapor cloud and drop atomization behavior. In addition the combustion of organic liquids like ethanol and pentanol can be seen directly with an increase of emitted radiation. A direct correlation between vapor cone and liquid properties can be made. Lower Ohnesorge numbers lead to more focused vapor beams.
\end{abstract}

(c) 2012 Elsevier B.V. All rights reserved.

\section{Introduction}

Liquid injection plasma spraying is one of the most versatile innovations in thermal spraying of the last decade. The possibility to manufacture finely structured coatings by submicronic to nanometric powders in suspension plasma spraying (SPS) [1-3] and vary stoichiometry by in-flight synthesis of liquid precursors in solution precursor plasma spraying (SPPS) [4-6] has made liquid injection a valuable addition to established thermal spray technologies. Especially future technology applications like solid oxide fuel cells benefit greatly from fine structures and flexible stoichiometry [7-11]. Though there has been put great effort into modeling of liquid injection into various plasmas and many parameters controlling liquid injection are known [12-17], there is little experimental data on the temporal evolution of liquid drops within the plasma and after the evaporization of the liquid carrier.

This work will present novel images of the drop behavior in atmospheric plasma jets. The results lead to a simplified modeling approach calculating the drop trajectories and by that estimating the plasma momentum acting on the drops. Infrared imaging technology is used to detect infrared radiation from the hot vapor of the liquid.

\section{Experimental setup}

Plasma source in the experiments was the industry standard Sulzer-Metco TriplexPro 200 atmospheric plasma torch. In all experiments the torch was set on constant current mode and argon as well as additionally helium was used as plasma gases. Current ranged from 200 to $500 \mathrm{~A}$ at different nozzle diameters of 5.5 to $11 \mathrm{~mm}$. Process gases were set to 30 to 90 slpm argon and helium was varied from

\footnotetext{
* Corresponding author. Tel.: + 497116862299.

E-mail address: Dennis.Soysal@DLR.de (D. Soysal).
}

0 to $20 \mathrm{slpm}$. Liquid was fed by a pressure based, semi-automatic feeding system.

Point of injection was placed $5 \mathrm{~mm}$ downstream from torch nozzle exit. The electronically controlled feeding gas pressure varied between 0.1 and $0.5 \mathrm{MPa}$ and ensured a constant liquid flow through 0.2 and $0.3 \mathrm{~mm}$ solid stream nozzles. For crisp images of liquid drops inside the plasma high speed camera from Photron FASTCAM SA5@ was used at a shutter time of 380 ns. The camera has a resolution of $1024 \times 1024$ pixels and combined with Carl Zeiss objectives gives a theoretical resolution of $8.7 \mu \mathrm{m}$ per pixel. This results in a minimal particle size of $26 \mu \mathrm{m}$. All images were taken in perpendicular to injection and plasma axis in shadowgraphy setup. Therefore a high power $750 \mathrm{~W}$ halogen spot light was set on camera axis on the opposite side of the plasma. Its high light flux density exceeded that of the plasma and made drops inside the plasma observable against the bright background. The frame rate between 75,000 and 150,000 frames per second ensured the capture of a temporal sequence of the liquid behavior. For the injection images with long exposure times of $250 \mathrm{~ms}$ the shadowgraphy setup of previous publication was used with a CW-laser and a high resolution camera [18].

The liquid vapor phase and combustion gases were detected by its infrared emission between 1.5 and $5 \mu \mathrm{m}$ with an infrared camera from FLIR@ SC7600 in the same experimental setup without background illumination. Here the frame rate was limited to $50 \mathrm{~Hz}$. Liquids studied in this work were water, ethanol and pentanol without any additives.

\section{Results}

\subsection{Injection quality}

Injecting a liquid into plasma is very different from conventional powder injection. Former consists of solid particles with well understood behavior and trajectories whereas liquids injected into plasma 
undergo several effects like atomization and vaporization. The infrared camera can capture radiation coming from hot water vapor which emits around $2.6 \mu \mathrm{m}$ [19]. Images with a spectral line filter with a line width of $200 \mathrm{~nm}$ showed that emission was significantly higher at this wavelength compared to images that use a line filter at $3.99 \mu \mathrm{m}$. This implies that the camera was detecting hot water vapor. Fig. 1 shows infrared images of plasmas with and without water injection. The conditions for liquid injections were the same $-20 \mathrm{ml} / \mathrm{min}$. Fig 1a shows the plasma jet without injection. Here the core of the plasma is displayed in uniform brightness without structure because it was saturating the camera pixels. The dynamic range of the camera was too low to depict plasma and vapor cloud at the same time. In the shown images spectral filters were not used to get the highest possible light yield and thereby reduce the integration time for more crisp and clear images with as little motion blur as possible. Very clearly a new extended plume is visible compared to pictures without injection. This can be attributed to hot water vapor from the atomized and evaporated liquid injection. Fig. 1b shows an image of a nearly optimal liquid injection. The water vapor plume is on the same axis with the plasma jet and the radiation intensity is higher compared to Fig. 1c. The only difference between the two pictures is an increased argon flow rate at constant current of $500 \mathrm{~A}$. Fig. 1b has 50 slpm argon and Fig. 1c 90 slpm argon. At 90 slpm argon the water injection was non-optimal since the core of the water vapor plume was shifted off the axis of the plasma. The plasma momentum has increased to a level that the solid water stream cannot penetrate the core of the plasma and was deflected on top of it. These two characteristics can be used to qualify a liquid injection - vapor plume intensity and vapor plume center.
Images with high shutter speed of 380 ns showed very clearly individual droplets, but to compare the atomization behavior it was necessary to merge 200 pictures that cover a time span of about $280 \mathrm{~ms}$ into one picture. Fig. $2 \mathrm{a}$ and b shows such pictures at the same conditions as Fig. 1b and c. It can be seen very clearly that the liquid stream is penetrating deeper into the plasma at 50 slpm than with 90 slpm Argon. The more droplets reach the hot plasma core and thus lead to a centered vapor cloud as seen in Fig. 1b. In Fig. 2b the water did not penetrate the plasma. Drops did not reach the core and only vaporized at the outer boundaries of the plasma. This explains the hot vapor stream at the top of the plasma jet in Fig. 1c.

\subsection{Atomization and vaporization characteristics}

More detailed analysis of atomization processes and vapor cloud examination complement each other. Three different liquids with different liquid properties are selected (Table 1).

The difference in surface tension and viscosity leads to a very different set of atomization behavior. Water and ethanol have similar viscosities whereas their surface tension differs by a factor of almost four. Pentanol and ethanol on the other hand have similar surface tensions but their viscosity again differs almost by a factor of four. All three differ in the energy released by combustion. Also emission of $\mathrm{OH}$ radicals during combustion has to be considered, although infrared radiation is governed by the main combustion products $\mathrm{CO}_{2}$ and $\mathrm{H}_{2} \mathrm{O}$ [24]. All this has to be taken into account when interpreting infrared images. Fig. 3 shows still infrared images at an exposure time of $35 \mu$ s with same injection settings and plasma
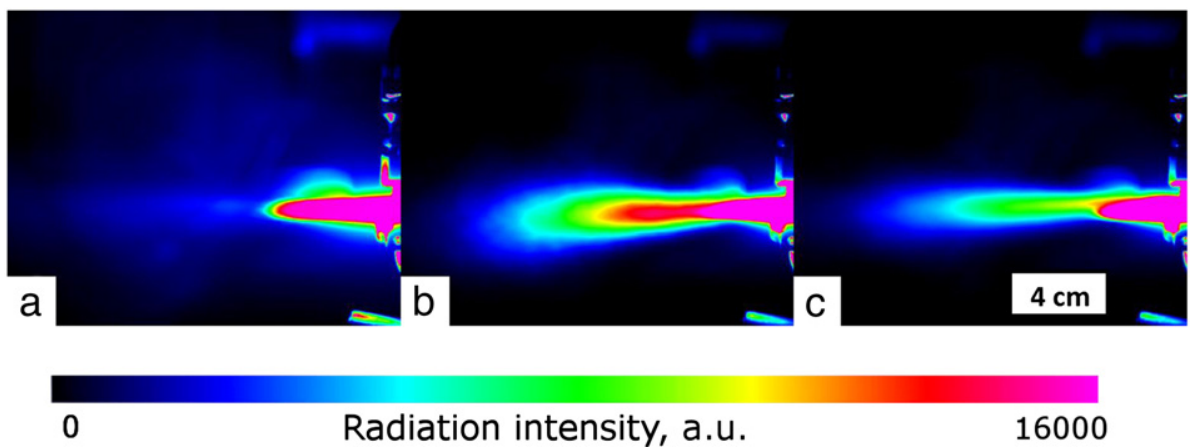

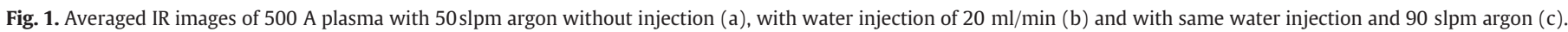

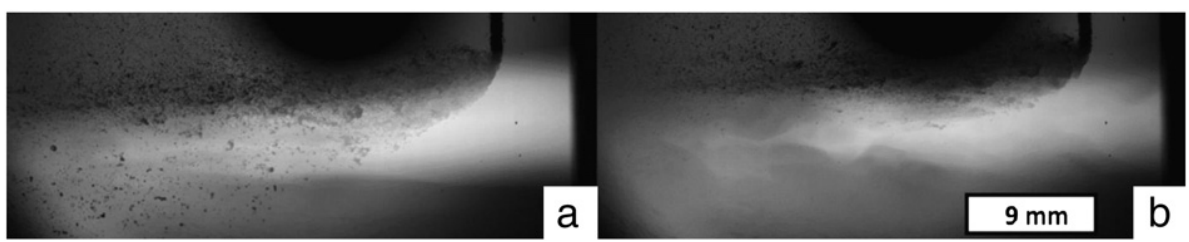

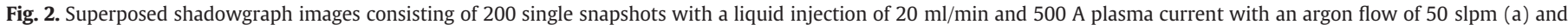
$90 \mathrm{slpm}(\mathrm{b})$

Table 1

Table of selected liquids and their physical properties for injection flow rate of $25 \mathrm{ml} / \mathrm{min}$.

\begin{tabular}{llllll}
\hline & $\begin{array}{l}\text { Surface } \\
\text { tension, } \\
\mathrm{nN} / \mathrm{m}\end{array}$ & $\begin{array}{l}\text { Viscosity, } \\
\mathrm{kg} /(\mathrm{m} * \mathrm{~s})\end{array}$ & $\begin{array}{l}\text { Density, } \\
\mathrm{kg} / \mathrm{m}^{3}\end{array}$ & $\begin{array}{l}\text { Enthalpy of } \\
\text { vaporization, } \mathrm{kJ} / \\
\text { min }\end{array}$ & $\begin{array}{l}\text { Energy of } \\
\text { combustion, } \\
\mathrm{MJ} / \mathrm{min}\end{array}$ \\
\hline Water & 72.88 & 1.0 & 0.99 & -55.9 & \\
Ethanol & 22.55 & 1.19 & 0.79 & -16.6 & 0.57 \\
Pentanol & 25 & 4.0 & 0.81 & -10.2 & 0.70 \\
\hline
\end{tabular}

conditions. Fig. 3a shows a still image of water injected into the plasma. The vapor plume is very short and weak in intensity compared to the other two plumes. The absolute intensities have to be interpreted carefully since the camera only detects a small band of infrared radiation from $1.5 \mu \mathrm{m}$ to $5 \mu \mathrm{m}$ and in these two dimensional images intensities also depend on concentration densities of emitting species. Therefore when comparing different liquids focus had to be set on geometrical dimensions and gradients of intensity 

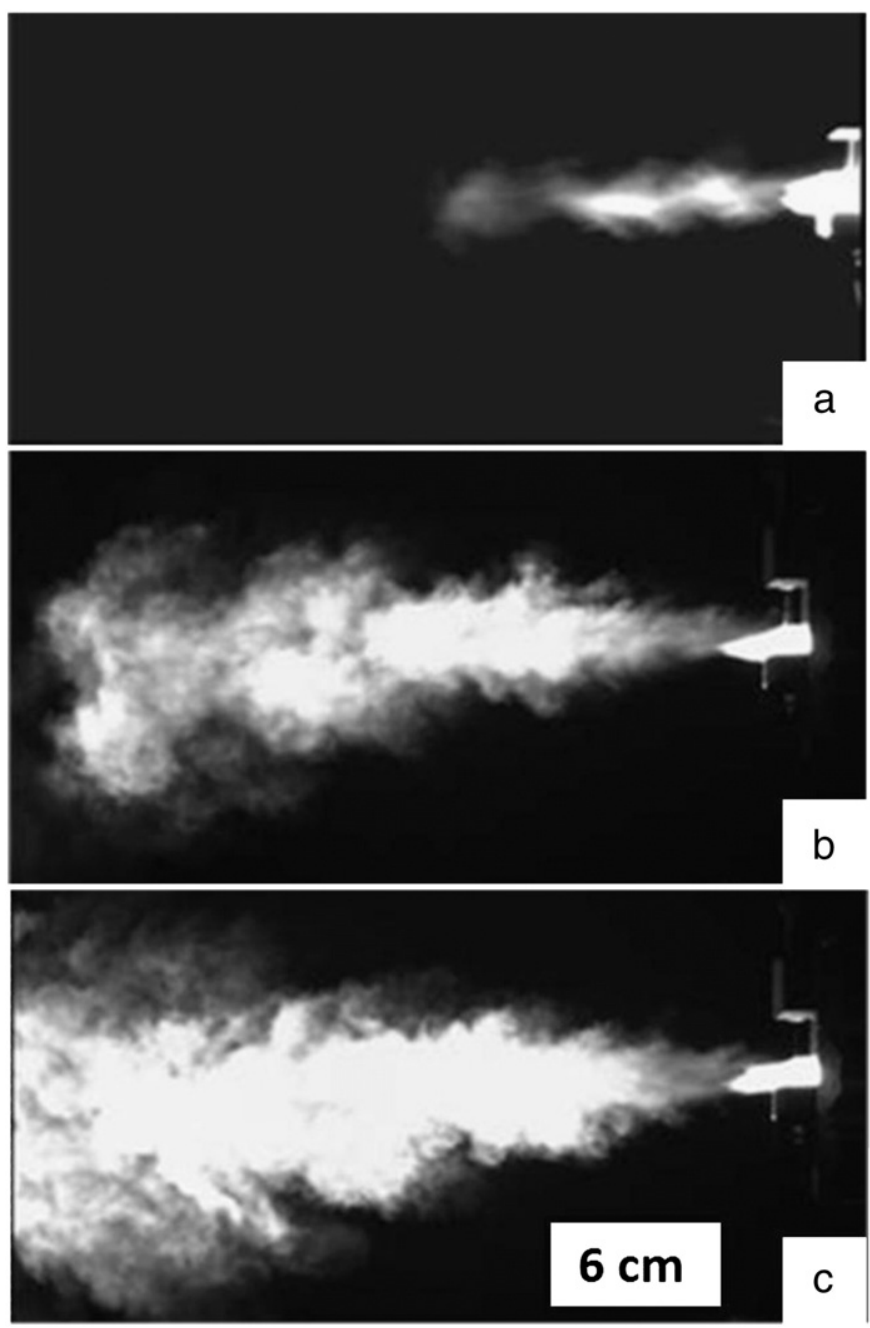

Fig. 3. Infrared images of different liquid injections at same conditions of $500 \mathrm{~A}$, 50 slpm $\mathrm{Ar}$ and $20 \mathrm{ml} / \mathrm{min}$ of the following liquids (a) water, (b) ethanol and (c) pentanol.

distribution. The exposure time of $35 \mu$ s was short enough to reveal fine structures in the vapor plumes. Especially at the plume boundaries turbulence was responsible for the jagged plume shapes.

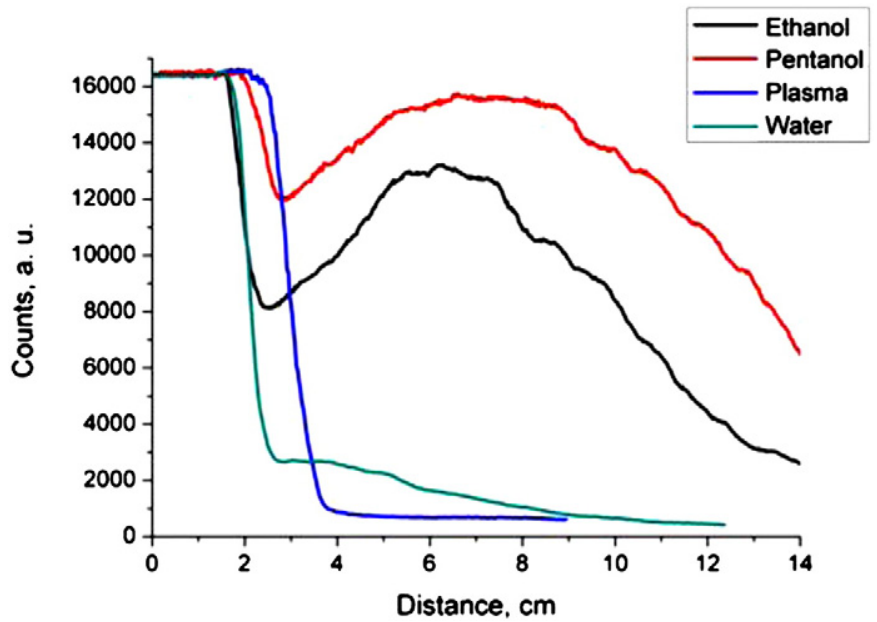

Fig. 4. Line profile along the plasma gun axis of averaged infrared images [500 A 50 slpm Ar, $20 \mathrm{ml} / \mathrm{min}$ ]
The chaotic nature of turbulence makes it necessary to examine average pictures made of 100 single snapshots. Fig. 4 shows line profiles along the plasma gun axis of averaged infrared images of water, ethanol and pentanol injection as well as the line profile of the plasma plume without any injection. Most prominently in the middle of the graph two maxima of radiation of ethanol and pentanol are discovered. In contrast to water which has no single maximum but shows a slow gradual drop to zero. The vapor cloud leaves the plasma with maximum energy and the further rise of radiation intensity can only be attributed to an energy gain from a source that is not the plasma. These maxima might come from post atomization combustion. This combustion process has a significant impact in areas where the oxygen attains a critical concentration. Combustion of organic fuels takes place outside the hot plasma plume where surrounding air is entrained. The difference between ethanol and pentanol was also the maximum of radiation was reached at a closer distance for ethanol than for pentanol. The peak width for ethanol is also narrower than for pentanol, which suggests a faster combustion process. Pentanol has a broad combustion peak in the infrared line profile that is also higher than for ethanol. An explanation could be the higher energy of combustion released by pentanol than ethanol.

Another effect observed in the infrared images was the length of the plasma plume. Whereas the plasma without injection is approximately $3 \mathrm{~cm}$ long it was shortened to 2.4 and $2.0 \mathrm{~cm}$ by pentanol and respectively ethanol injection. Water and ethanol have the same influence on plasma plume length, which might be correlated to their similar viscosity. Pentanol has a four times higher viscosity and the plume length is significantly longer. In Fig. 5 top row single snapshots of liquids injected into same plasma conditions are displayed. They show all states of atomization a liquid droplet undergoes. The shortening of the plasma can be explained by the different atomization behavior. Whereas in the case of water and ethanol different stages of atomization can be distinguished - sheet stripping to wave crest stripping mode - pentanol is atomized right at the point of penetration. Water and ethanol interfere severely with the plasma and thus shorten its length. Pentanol is very easily atomized into fine droplets which do not weaken the radiation of the plasma as much as water and ethanol droplets do. This weakening could be attributed to a loss of power by the energy drained for atomization and evaporization as well as it could simply be an effect of clouding/shading by the larger drops since they can scatter and absorb radiation from the plasma.

In Fig. 3 the spray cone of the three liquids also differs. Pentanol has the biggest and broadest spray cone of all the liquids used. Fig. 6 shows spray angles derived from averaged infrared images by image analysis software ImageJ. Water has a focused cone with an opening angle of about $15^{\circ}$ and pentanol has the biggest opening angle of about $28^{\circ}$. This behavior cannot be described by a single physical liquid property alone. The spray cone is influenced by the ease of atomization of every liquid since plasma flow conditions are the same. In literature [20] the Ohnesorge number is used as a measure of the atomizability of liquids. The Ohnesorge number is given by following equation:

$\mathrm{Oh}=\sqrt{ }(\mathrm{We}) / \operatorname{Re}=\mu /(\mathrm{L} * \rho * \sigma)$.

We is the Weber number, Re is the Reynolds number, $\mu$ is the viscosity, $\mathrm{L}$ is the characteristic dimension, $\rho$ is the density and $\sigma$ is the surface tension of the liquid. The higher the Ohnesorge number the lower the relative speed of the surrounding gas stream and its Reynolds number has to be to atomize the liquid [21]. As characteristic length the solid stream diameter of $260 \mu \mathrm{m}$ is chosen, since it represents the common start of atomization for all liquids. The calculated Ohnesorge numbers for the tested liquids are shown in Fig. 6. Ethanol has a twofold higher Ohnesorge number than water. Furthermore pentanol has a three times higher Ohnesorge number than ethanol.

Shadowgraphy images in Fig. 5a-c confirm this correlation. From left to right atomization was happening at an earlier stage of penetration. The superposition of many frames in the second row (Fig. 5d-f) on the other hand seems to show the opposite formation of spray cones. 


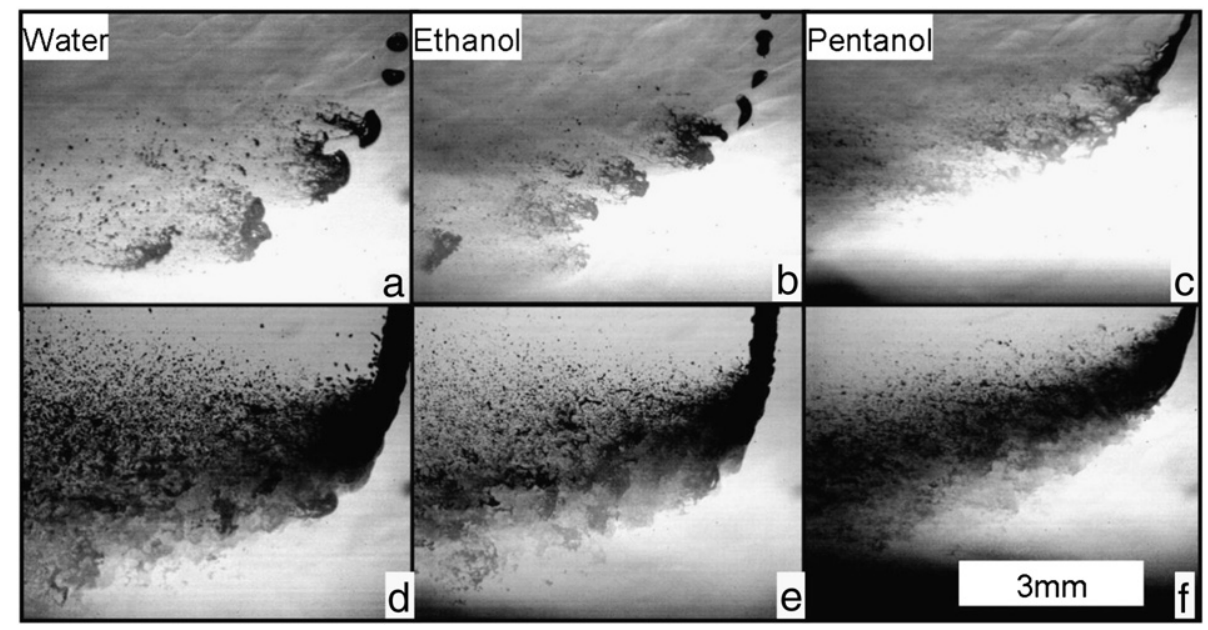

Fig. 5. Top row - still images of different liquid injection into the same plasma [500 A, $50 \mathrm{slpm} \mathrm{Ar,} 20 \mathrm{ml} / \mathrm{min}]$ and bottom row - superposed image.

Water formed a broader spray cone than pentanol. The explanation is that water remains longer in droplet form and is accelerated into jet direction while it is evaporating. On Fig. 3a only the vapor cloud is shown. Pentanol was already fragmented into fine droplets upon entering the plasma. Its droplets evaporated faster than the bigger water droplets; meanwhile its gas phase was expanding and thus creating a radial momentum. The vapor was being pushed sideways by the pressure gradient between the accelerating plasma and decelerating atmosphere. Following that explanation there is a correlation between Ohnesorge number and spray cone angle, but it is not linear. For optimal deposition efficiency a more focused spray cone could be advantageous. Further work has to show how far particles follow the vapor and thus the spray spots are broadened with increasing Ohnesorge number.

\section{Conclusion}

Infrared imaging has shown to be an innovative, valuable tool in addition to already established diagnostic systems like tomography, enthalpy probe, etc. Its combination with high speed shadowgraphy improves the understanding of the atomization and evaporization processes. Infrared imaging visualizes the hot gases coming from plasma and high speed shadowgraphy opens up a detailed view on the atomization processes leading up to the vapor cloud. Infrared images proved that the additional energy coming from combustion of organic liquids can be revealed. An extensive study of plume characteristics in the infrared spectral range has shown a correlation between spray cone angle and used fluid. Together with high speed shadowgraphy this correlation between atomization and the resulting vapor cloud has been linked to the Ohnesorge number. The lower the Ohnesorge number the more focused is the vapor stream.

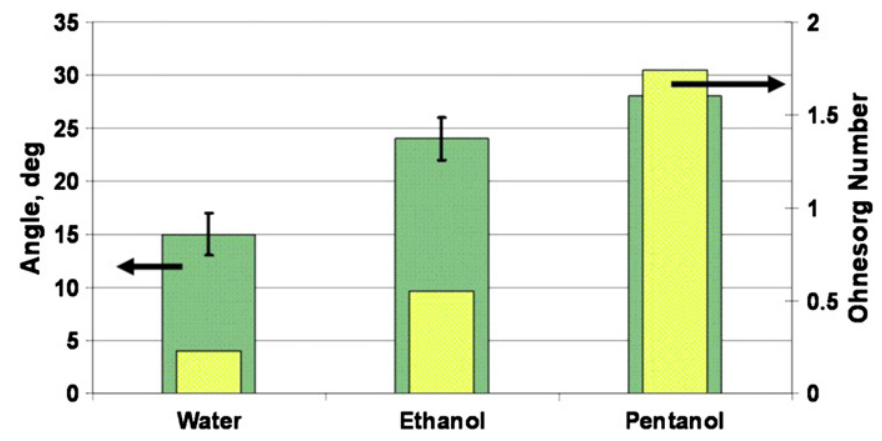

Fig. 6. Spray angle (green) and Ohnesorge number (yellow) of tested liquids.
Enthalpy probe measurements as shown by Vaßen et al. [22,23] are a valuable addition to optical methods to analyze the influence of liquids on plasma characteristics. Atomization of more organic liquids has to be tested and observed by high speed shadowgraphy to better understand the difference in droplet behavior.

\section{References}

[1] D. Chen, E. Jordan, M. Gell, J. Therm. Spray Technol. 18 (3) (2009) 421.

[2] K. Jeganathan, C.B. Christopher, R. Sri, W. Jenn-Yue, H.K. Alexander, H. Herbert, J. Am. Ceram. Soc. 81 (1) (1998) 121.

[3] L. Pawlowski, Surf. Coat. Technol. 202 (18) (2008) 4318.

[4] L. Jia, F. Gitzhofer, J. Therm. Spray Technol. 19 (3) (2010) 566.

[5] A. Ozturk, B.M. Cetegen, Mater. Sci. Eng., A 384 (1-2) (2004) 331.

[6] J.L. Dorier, P. Guittienne, C. Hollenstein, M. Gindrat, A. Refke, Surf. Coat. Technol. 203 (15) (2009) 2125

[7] C.C.D. Soysal, A. Ansar, ECS Trans. 25 (2) (2009) 601

[8] A. Ansar, D. Soysal, G. Schiller, Int. J. Energy Res. 33 (13) (2009) 1191.

[9] D. Soysal, C. Christenn, A. Ansar, in: Workshop Plasma- und Oberflächentechnik, XVI, 2009, p. 12

[10] Y. Chen, S. Omar, A.K. Keshri, K. Balani, K. Babu, J.C. Nino, S. Seal, A. Agarwal, Scr. Mater. 60 (11) (2009) 1023.

[11] I.R. Gibson, G.P. Dransfield, J.T.S. Irvine, J. Eur. Ceram. Soc. 18 (6) (1998) 661.

[12] N.P. Padture, K.W. Schlichting, T. Bhatia, A. Ozturk, B. Cetegen, E.H. Jordan, M. Gell, S. Jiang, T.D. Xiao, P.R. Strutt, E. García, P. Miranzo, M.I. Osendi, Acta Mater. 49 (12) (2001) 2251.

[13] S.A. Esfarjani, A. Dolatabadi, Surf. Coat. Technol. 203 (15) (2009) 2074.

[14] D. Waldbillig, O. Kesler, Surf. Coat. Technol. 203 (15) (2009) 2098.

[15] C. Marchand, A. Vardelle, G. Mariaux, P. Lefort, Surf. Coat. Technol. 202 (18) (2008) 4458.

[16] P. Fauchais, V. Rat, J.F. Coudert, R. Etchart-Salas, G. Montavon, Surf. Coat. Technol 202 (18) (2008) 4309.

[17] L. Pawlowski, Surf. Coat. Technol. 203 (19) (2009) 2807.

[18] A.A. Dennis Soysal, in: International Thermal Spraying Conference Proceeding, 2011, p. 1307.

[19] J. Tennyson, P.F. Bernath, L.R. Brown, A. Campargue, M.R. Carleer, A.G. Császár, R.R. Gamache, JT. Hodges, A. Jenouvrier, O.V. Naumenko, O.L. Polyansky, L.S. Rothman, R.A. Toth, A.C. Vandaele, N.F. Zobov, L. Daumont, A.Z. Fazliev, T. Furtenbacher, I.E. Gordon, S.N. Mikhailenko, S.V. Shirin, J. Quant. Spectrosc. Radiat. Transfer 110 (9-10) (June-July 2009) 573.

[20] W. Mayer, R. Branam, Exp. Fluids 36 (4) (2004) 528

[21] A.H. Lefebvre, Atomization and Sprays, Hemisphere Pub. Corp., 1989.

[22] G. Mauer, A. Guignard, R. Vaßen, D. Stöver, Surf. Coat. Technol. 205 (4) (2010) 961, http://dx.doi.org/10.1016/j.surfcoat.2010.03.007.

[23] R. Vaßen, H. Kaßner, G. Mauer, D. Stöver, J. Therm. Spray Technol. 19 (1-2) (2009) 219, http://dx.doi.org/10.1007/s11666-009-9451-x.

[24] P.F. Bernath, Annu. Rep. Prog. Chem. Sect. C: Phys. Chem. 96 (1) (2000) 177, http: //dx.doi.org/10.1039/b001200i. 